\title{
Pillared clays from natural resources as catalysts for catalytic wet peroxide oxidation: Characterization and kinetic insights
}

\author{
Marzhan Seitovna Kalmakhanova ${ }^{1}$, Jose Luis Diaz de Tuesta ${ }^{2,3^{\dagger}}$, \\ Bakytgul Kabykenovna Massalimova ${ }^{1}$, Helder Teixeira Gomes ${ }^{2,3^{+}}$ \\ ${ }^{1}$ Department of Chemistry and Chemical Engineering, M.Kh. Dulati Taraz State University, Taraz, Kazakhstan \\ ${ }^{2}$ Mountain Research Center CIMO, Polytechnic Institute of Bragança, 5300-253 Bragança, Portugal \\ ${ }^{3}$ Laboratory of Separation and Reaction Engineering - Laboratory of Catalysis and Materials (LSRE-LCM), Faculty of Engineering of the University of \\ Porto (FEUP), Rua Dr. Roberto Frias, 4200-465 Porto, Portugal
}

\section{ABSTRACT}

Pillared clays with $\mathrm{Zr}$ and $\mathrm{Fe} / \mathrm{Cu} / \mathrm{Zr}$ polycations have been prepared from natural clays found in large deposits of Kazakhstan and assessed as catalysts for the catalytic wet peroxide oxidation (CWPO), using 4-nitrophenol (4-NP) as model compound. The performance of the catalysts was followed by measuring the concentration of $4-\mathrm{NP}, \mathrm{H}_{2} \mathrm{O}_{2}$ and the total organic carbon (TOC), considering $\mathrm{C}_{4-\mathrm{NP}}=5 \mathrm{~g} \mathrm{~L}{ }^{-1}, \mathrm{C}_{\mathrm{H}_{2} \mathrm{O}_{2}}=17.8$ $\mathrm{g} \mathrm{L}^{-1}, \mathrm{C}_{\text {cat }}=2.5 \mathrm{~g} \mathrm{~L}^{-1}$, initial $\mathrm{pH}=3.0$ and $\mathrm{T}=50^{\circ} \mathrm{C}$. At those selected conditions, the pillared clays showed higher activity than natural clays in the CWPO of 4-NP. The conversion of the model pollutant was complete when $\mathrm{Fe} / \mathrm{Cu} / \mathrm{Zr}$-PILCs were used, with the TOC removal reaching $78.4 \%$ after $24 \mathrm{~h}$ with the best $\mathrm{Fe} / \mathrm{Cu} / \mathrm{Zr}$-PILC. The $\mathrm{H}_{2} \mathrm{O}_{2}, 4-\mathrm{NP}$ and TOC time-evolution was well described by a kinetic model based on TOC lumps in three blocks, considering the initial TOC (corresponding to 4-NP), the production of oxidizable intermediates and the formation of refractory products.

Keywords: Advanced oxidation process, Clay-based catalyst, CWPO, Kinetic modeling, Wastewater treatment, 4-nitrophenol

\section{Introduction}

In modern life, especially in productive activities, water plays an important role. There are about 39 thousand rivers and temporary streams in Kazakhstan. Among them, over 7 thousand are more than $10 \mathrm{~km}$ long. Most of the rivers in Kazakhstan belong to the internal closed drainage basins of the Caspian and Aral Seas and Balkhash, Alakol and Tengiz Lakes [1]. The majority of industries are situated around these rivers and lakes in order to use the water and to enable the discharge of some effluents for the aquatics systems. However, some of those streams can be harmful, making nowadays the contamination one of the primary issues of environmental authorities, requiring solutions in order to reduce its impact by using effective and inexpensive wastewater treatment methods, such as advanced oxidation processes (AOPs).

Nowadays, the scientific community shows an increasing interest in the development of AOPs (e.g., Fenton process, photo catalytic oxidation and electro catalytic oxidation) for the removal of recalcitrant and non-biodegradable organic compounds from aqueous streams. AOP are particularly useful technologies to treat recalcitrant or non-degradable compounds present in wastewaters in a wide range of concentrations (0.1-10 g/L) [2,3], difficult to remove by the conventional biological processes. The Fenton process consists on the use of iron and hydrogen peroxide, commonly known as Fenton's reagent $\left(\mathrm{H}_{2} \mathrm{O}_{2}+\mathrm{Fe}^{2+}\right)$, for the generation of hydroxyl radicals $\left(E_{0}^{o}=2.80 \mathrm{~V}\right)$, highly oxidizing species capable of degrading the organic matter present in wastewater effluents. The loss of the homogeneous catalyst is a major drawback that limits in practice the application of the Fenton process [4], since there is the necessity of a continuous feeding of iron and the corresponding additional separation processes and sludge disposal. In addition, although the Fenton process can completely destroy organic pollutants to harmless products, it requires a tight range of $\mathrm{pH}$ to operate (typically between 2 and 3, depending on the effluent [5]), and the need
This is an Open Access article distributed under the terms of the Creative Commons Attribution Non-Commercial License (http://creativecommons.org/licenses/by-nc/3.0/) which permits unrestricted non-commercial use, distribution, and reproduction in any medium, provided the original work is properly cited.

Copyright (C) 2020 Korean Society of Environmental Engineers
Received November 14, 2018 Accepted March 3, 2019

${ }^{\dagger}$ Corresponding author

Email: jl.diazdetuesta@ipb.pt, htgomes@ipb.pt

Tel: +351-273-303-110 Fax: +351-273-313-051

ORCID: 0000-0003-2408-087X (J. L. Diaz de Tuesta) 
for further recovery of the precipitated catalyst $[5,6]$, reducing its popularity to be applied widely in industries. In order to avoid the inconveniences found in Fenton oxidation, in the last decades researchers have tested a variety of heterogeneous catalysts as alternatives, using hydrogen peroxide as an oxidizing agent. The oxidation process with $\mathrm{H}_{2} \mathrm{O}_{2}$ considering a heterogeneous catalyst in commonly known as catalytic wet peroxide oxidation (CWPO). CWPO is one of the promising methods for the removal of organic pollutants at mild temperature and pressure conditions $[7,8]$, providing that a suitable catalytic system is used, such as catalysts based on natural and pillared clays (PILCs).

PILCs are porous materials developed by molecular design methods, obtained by exchanging the cations of alkaline and alkaline earth metals, located in the interlayer space of clays, by inorganic polyoxo (hydroxo) cations. To prepare PILCs, intercalating salt solutions of $\mathrm{Al}, \mathrm{Cu}, \mathrm{Cr}, \mathrm{Zr}, \mathrm{Fe}, \mathrm{Zn}$ and other active metals are usually used [8-10]. The use of these metals, combined as polyoxycations, are of greatest interest since they lead to high thermal stability [9]. By changing the nature and, hence, the size of the pillars, different pore-sizes are obtained; and it becomes possible to tune the porosity. This porosity, coupled with the properties of different pillars and host, are very important for certain applications [9]. Previous work shows that the intercalation of different pairs of cations on natural clays, as zirconium $(\mathrm{Zr})$, copper $(\mathrm{Cu})$, iron $(\mathrm{Fe})$, leads to improved catalytic activity for the oxidation of organic compounds, mainly tested with phenol, extensively used as model pollutant [10]. In CWPO, PILCs have been used as catalysts, taking advantage of its porous structure to adsorb organic compounds on its surface, which actively participates in the oxidation process in the presence of hydrogen peroxide. The use of 4-nitrophenol (4-NP) as model compound to assess the performance of catalytic systems in AOPs has been less explored than phenol, the mechanistic insights lacking consolidated data. However, few reports in CWPO [11-14], photo oxidation by $\mathrm{UV} / \mathrm{H}_{2} \mathrm{O}_{2}$ [15] and, in previous works on our group by CWPO with reduced graphene oxide materials [16], magnetic carbon xerogels [17] and carbon nanotubes [2], reveal that the main reaction intermediates are hydroquinone, benzoquinone, catechol and several low molecular weight carboxylic acids (e.g., malonic, malic, maleic and acetic acids). To the best of our knowledge, there are no works related to the development of kinetic models for the CWPO of 4-NP and nowadays most of the studies regarding CWPO processes present only pseudo-first order rate equations describing the disappearance of a target pollutant [18].

4-NP is a toxic and bio-refractory compound that can damage the central nervous system, liver, kidney and blood of humans and other living beings. It has been shown in the literature that 4-NP can develop a blood disorder which reduces the ability of the blood to carry oxygen to tissues and organs $[19,20]$. Thus, the use of 4-NP as model compound in AOP studies and the knowledge of its degradation mechanism and kinetics are of highly importance.

In this study, we report the results obtained in the CWPO of 4-NP in aqueous reaction media (used as model synthetic wastewater) considering monometallic $(\mathrm{Zr})$ and trimetallic $(\mathrm{Fe} / \mathrm{Cu} / \mathrm{Zr})$ PILCs prepared from natural clays extracted from Akzhar and Karatau (Kazakhstan) deposits, using zirconium tetrachloride, copper sulphate and ferrous sulphate as pillaring cation precursors. The catalytic activity of the prepared PILCs is compared to the extracted natural clays and a kinetic model is developed for the CWPO of $4-\mathrm{NP}$.

\section{Materials and Methods}

\subsection{Reagents and Chemicals}

Clays were obtained from the Karatau and Akzhar deposits (located in the Zhambyl region of south of Kazakhstan). Zirconium tetrachloride, reactor grade (99.5\%), was supplied from Alfa Aesar, and ferrous sulphate heptahydrate (99.5\%) and copper sulphate pentahydrate (99.9\%) were obtained from Skat reactives. Hydrogen peroxide $(30 \% \mathrm{w} / \mathrm{v})$, used as oxidant in the treatment of the synthetic wastewater, was purchased from Fluka. Titanium (IV) oxysulphate ( $\mathrm{TiOSO}_{4}, 15$ wt.\% in dilute sulphuric acid, 99.99\%), hydrochloric acid ( $\mathrm{HCl}, 37$ wt.\%) and sodium sulphite $\left(\mathrm{Na}_{2} \mathrm{SO}_{3}, 98\right.$ wt.\%) were purchased from Sigma-Aldrich. Sodium hydroxide (NaOH, 98 wt.\%) was obtained from Panreac. 4-NP (98 wt.\%) and 4-nitrocatechol (98 wt.\%) were acquired from Acros Organics and Fluka, respectively. Methanol (HPLC grade), glacial acetic acid (analytical reagent grade) and acetonitrile (HPLC grade) were obtained from Fisher Chemical. All chemicals were used as received without further purification. Distilled water was used throughout the work.

\subsection{Preparation of Pillared Clays}

Two natural clays extracted from Karatau (KNC) and Akzhar (ANC) deposits were used as raw materials to prepare the pillared clays. First, the extracted natural clays were extensively washed with $\mathrm{HCl}(2 \mathrm{M})$ at $50^{\circ} \mathrm{C}$, in order to eliminate non-bonded content of metal and other contaminants present inside the clays. Pillared clays were then prepared from the washed natural clays, using zirconium tetrachloride as a source of zirconium polycations. Ferrous sulphate and copper sulphate were used as source of iron and copper polycations. The pillaring solution was prepared by slow addition of $\mathrm{NaOH}(0.2 \mathrm{M})$ to the solution containing the polycation precursors at room temperature until $\mathrm{pH}=2.8$ were obtained. The resultant solution was aged for $24 \mathrm{~h}$ at room temperature. The clay pillaring process kept a ratio of $10 \mathrm{mmol}$ of total metal per gram of washed clay, irrespective $\mathrm{Zr}$-PILCs or $\mathrm{Fe} / \mathrm{Cu} / \mathrm{Zr}$-PILCs were prepared. The final materials were dried at $350 \mathrm{~K}$ for $24 \mathrm{~h}$ and calcined during $2 \mathrm{~h}$ at $823 \mathrm{~K}$ considering a heating rate of $275 \mathrm{~K} \mathrm{~min}^{-1}$.

\subsection{Characterization Methods}

The physico-chemical characteristics of the natural and pillared clays were determined by X-ray spectral analysis performed with a spectrometer Inca Energy from Oxford instruments, using an electron microprobe (EMP) of the brand Superprobe 733 from JEOL. $\mathrm{X}$-ray diffraction analysis was performed on an automated diffractometer DRON-3 with CuKa - radiation, $\beta$-filter. A semiquantitative basis was carried out on the diffraction patterns of powder samples using the method of equal weights and artificial mixtures. The diffraction patterns were interpreted using ICDD data: a base of powder diffractometric data PDF2 (Powder Diffraction File) and diffractograms of mineral-free impurities with the EVA program version 7.0. Scanning electron microscope (SEM) was performed on a FEIQuanta 400FEG ESEM/EDAX Genesis X4M instrument equipped with an 
energy dispersive spectrometer (EDS). Transmission electron microscopy (TEM) was performed in a LEO 906E instrument operating at $120 \mathrm{kV}$, equipped with a 4Mpixel $28 \times 28 \mathrm{~mm}$ CCD camera from TRS.

The $\mathrm{pH}$ of point of zero charge $\left(\mathrm{pH}_{P Z C}\right)$ was determined by $\mathrm{pH}$ drift tests, following the procedure described elsewhere [21,22]. Briefly, five $\mathrm{NaCl}(0.01 \mathrm{M})$ solutions were prepared as electrolyte and initial $\mathrm{pH}$ was adjusted to 2, 4, 6, 8 and 10 using $\mathrm{HCl}$ and $\mathrm{NaOH} 0.1 \mathrm{M}$ solutions. Then, samples of $0.05 \mathrm{~g}$ of pillared clays were loaded in each $20 \mathrm{~mL}$ of the previous solutions. The equilibrium $\mathrm{pH}$ of each suspension was considered after $48 \mathrm{~h}$ under stirring (320 rpm) at room temperature and, hence, the $\mathrm{pH}$ was measured (final $\mathrm{pH}$ ). The $p H_{P Z C}$ value was determined by intercepting the curve 'final $\mathrm{pH}$ vs initial $\mathrm{pH}$ ' with the straight line 'initial $\mathrm{pH}=$ initial $\mathrm{pH}$. Fourier Transform Infrared Spectroscopy (FTIR) spectra of natural and PILCs were obtained with a FTIR instrument (Infraspek, Model FSM 1201, Russia, St-Petersburg) with a resolution of $1 \mathrm{~cm}^{-1}$ and scan range of 7,800 to $400 \mathrm{~cm}^{-1}$ using a sample based on $1 \%$ of clay with $\mathrm{KBr}$.

\subsection{Catalytic Runs}

The CWPO of 4-NP in aqueous medium was carried out in a 250 $\mathrm{mL}$ well-stirred glass reactor maintained at $323 \mathrm{~K}$. The reactor was loaded with $100 \mathrm{~mL}$ of a concentrated (5.0 g/L) 4-NP aqueous solution, considered as a model system to simulate high-loaded wastewaters [2,23-25]. The initial $\mathrm{pH}$ of the solution was adjusted to 3 by adding $\mathrm{H}_{2} \mathrm{SO}_{4}$ and $\mathrm{NaOH}$ solutions (not buffered). The stoichiometric quantity of hydrogen peroxide needed for complete mineralization of 4-NP was then added. The catalyst was loaded (2.5 g/L) after homogenization of the resulting solution, that moment being considered as $t_{0}=0 \mathrm{~h}$. All experiments were carried out during $24 \mathrm{~h}$. Several samples were withdrawn from the medium of reaction at previously selected reaction times to follow the course of the 4-NP conversion and the appearance of intermediate compounds, measured by high-performance liquid chromatography (HPLC). For that purpose, a Jasco HPLC system equipped with a UV-Vis detector (UV-2075 Plus), a quaternary gradient pump (PU-2089 Plus) for solvent delivery

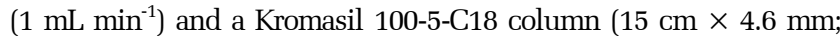
$5 \mu \mathrm{m}$ particle size; reversed-phase) was employed. Total Organic Carbon (TOC) and $\mathrm{H}_{2} \mathrm{O}_{2}$ concentrations were also measured during each run, using respectively a Shimadzu TOC-L CSN analyzer and a colourimetric method based on $\mathrm{TiOSO}_{4}$ [16].

\subsection{Kinetic Modelling}

The kinetic modelling of the CWPO results obtained with the natural clays Karatau and Akzhar and with the PILCs Fe-Cu-Zr-Karatau and Fe-Cu-Zr-Akzhar has been performed to describe the time-course evolution of 4-NP (used as target pollutant), $\mathrm{H}_{2} \mathrm{O}_{2}$ and TOC concentrations, following the procedures described elsewhere $[18,22]$. The rate of disappearance of each given compound (i) in the reaction medium, $r_{i}\left(\mathrm{~mol} \mathrm{~g}^{-1} \mathrm{~s}^{-1}\right)$, is given by Eq. (1):

$$
-r_{i}=\frac{1}{C_{c a t}} \frac{d C_{i}}{d t}
$$

where $C_{c a t}$ refers to the catalyst concentration $\left(\mathrm{g} \mathrm{L}^{-1}\right), C_{i}$ to the concentration of compound $\mathrm{i}$, such as $\mathrm{H}_{2} \mathrm{O}_{2}$, 4-NP or TOC (mol
$\mathrm{L}^{-1}$ ) and $t$ representing the time of reaction (h). The rate of disappearance $r_{i}$ can be expressed as a function of the concentration of the species involved in the reaction.

The numerical integration of the rate equations was solved by using the Microsoft Excel Solver (Microsoft Office 2010, Microsoft Corp.) for least-squares minimization. The models were also evaluated by the sum of square residual $(S S R)$ and determination factor $\left(R^{2}\right)$, calculated by applying Eq. (2) and Eq. (3), respectively:

$$
\begin{gathered}
S S R=\sum_{n=1}^{N}\left(C_{\text {exp } i, n}-C_{\text {model } i, n}\right)^{2} \\
R^{2}=\frac{\sum_{n=1}^{N}\left(C_{\text {model } i, n}-\overline{C_{\text {model } i}}\right)^{2}}{\sum_{n=1}^{N}\left(C_{\text {model } i, n}-\overline{C_{\text {model } i}}\right)^{2}+\sum_{n=1}^{N}\left(C_{\text {exp } i, n}-\overline{C_{\text {model } i, n}}\right)^{2}}
\end{gathered}
$$

\section{Results and Discussion}

\subsection{Characterization of the Natural Clays and PILCs}

\subsubsection{X-Ray diffraction}

The powder X-ray diffraction patterns of the natural clays are shown in Fig. 1. In the diffractogram of the natural clays, the peaks at $2 \theta=6.2^{\circ}\left(\mathrm{d}_{001}-14.19 \AA\right)$ and $2 \theta=19.9^{\circ}(\mathrm{d}=4.5 \AA)$ represents the characteristic reflection of montmorillonite (represented as $\mathrm{M}$ in Fig. 1), as reported by Is Fatimah [26]. The diffraction peaks at $(2 \theta) 20.85^{\circ}, 26.6^{\circ}, 36.5^{\circ}, 39.5^{\circ}$ and $50.1^{\circ}$ revealed the presence of quartz (as Q in Fig. 1), an impurity in the natural clays [13,26]. The reflections at $(2 \theta) 23.01^{\circ}, 29.5^{\circ}$ and $36.0^{\circ}$ was due to calcite (represented as C in Fig. 1) [27].

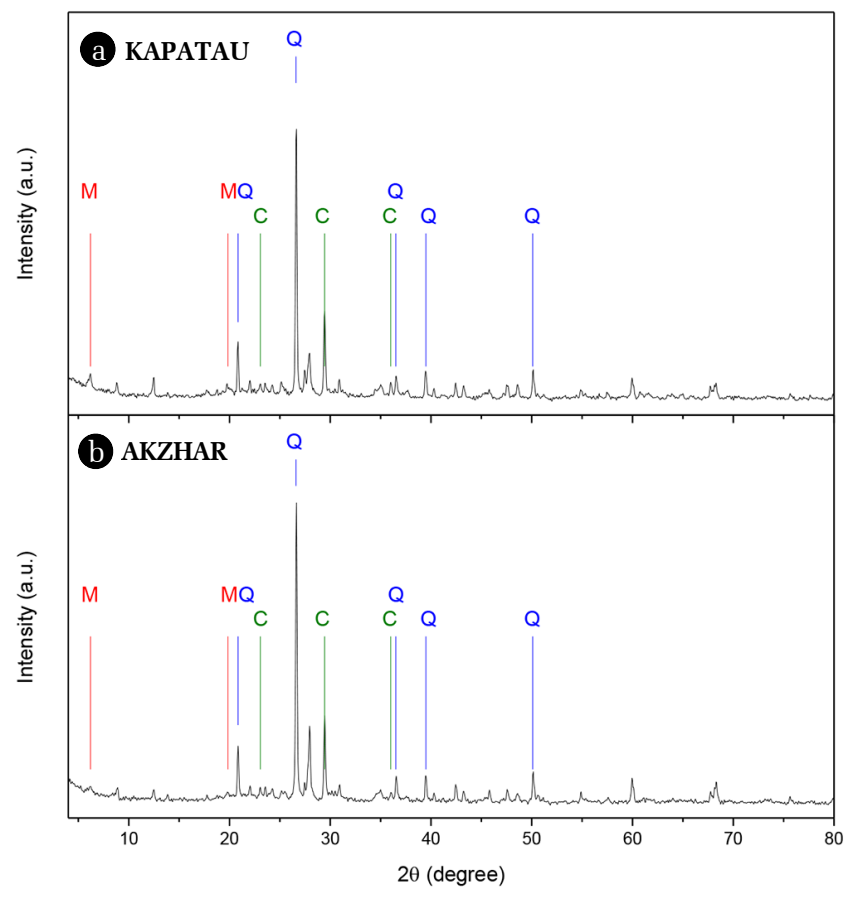

Fig. 1. X-ray diffraction spectra obtained for (a) KNC and (b) ANC (M: montmorillonite, Q: quartz, C: calcite). 
Table 1. Chemical Composition of the Natural and Pillared Clays, Determined by Elemental Analysis

\begin{tabular}{|c|c|c|c|c|c|c|c|c|c|c|c|}
\hline \multirow{2}{*}{ Clay } & \multicolumn{11}{|c|}{ Mass of the element (\%) } \\
\hline & $\mathrm{Na}$ & Mg & Al & Si & $\mathbf{K}$ & Ca & $\mathbf{T i}$ & Mn & $\mathbf{F e}$ & $\mathbf{C u}$ & $\mathbf{Z r}$ \\
\hline KNC & 1.7 & 4.8 & 13.9 & 44.8 & 4.8 & 16.2 & 3.4 & 0.5 & 9.9 & n.i. ${ }^{*}$ & n.i. * \\
\hline ANC & 1.8 & 4.9 & 13.2 & 48.4 & 4.8 & 18.3 & 0.7 & n.i. ${ }^{*}$ & 7.9 & n.i. ${ }^{*}$ & n.i. * \\
\hline Zr-APILC & 2.0 & 2.5 & 9.8 & 40.5 & 4.8 & 0.8 & 0.5 & n.i.* & 2.8 & n.i.* & 36.3 \\
\hline Zr-KPILC & 2.5 & 2.5 & 10.0 & 41.8 & 4.3 & 0.9 & 0.3 & n.i.* & 2.7 & n.i.* & 35.0 \\
\hline $\mathrm{Fe} / \mathrm{Cu} / \mathrm{Zr}-\mathrm{KPILC}$ & 3.7 & 3.3 & 13.4 & 47.5 & 3.9 & 1.3 & 0.7 & n.i. * & 11.5 & 9.6 & 5.1 \\
\hline $\mathrm{Fe} / \mathrm{Cu} / \mathrm{Zr}-\mathrm{APILC}$ & 1.9 & 2.6 & 11.9 & 46.4 & 5.6 & 1.2 & 0.6 & n.i. * & 22.8 & 6.1 & 0.9 \\
\hline
\end{tabular}

${ }^{*}$ n.i. $=$ not identified

A semi-quantitative analysis was carried out from the XRD spectra in order to determine the composition of the natural clays in quartz, muscovite, feldspar, calcite, hydrated aluminum silicate and Kaolinite was determined (Table S1). As can be observed, these natural clays contain a high quantity of impurities in form of quartz and calcite (56.7 and $45.9 \%$ for ANC and KNC, respectively).

The content of quartz on raw natural clays can be different depending on the deposit of the clay. Djeffal et al. [28] reported the use of natural clay with $53.86 \%$ in quartz in the CWPO of phenol. The calcite presented in the raw clays is normally replaced during cation exchange in the pillaring process, as done in this work.

\subsubsection{EMP}

The chemical composition of the natural and pillared clays is shown in Table 1, as determined by Inca Energy with a dispersive spectrometer from Oxford Instruments. As observed, the natural clays used in this work are rich in iron (7.9-9.9\%), which can play an important role in the decomposition of hydrogen peroxide to produce hydroxyl radicals for the oxidation of pollutants in CWPO. The analysis on the composition of the pillared clays indicates the successful enrichment of pillaring $\mathrm{Zr}$ cations in Zr-KPILC and Zr-APILC, by exchange with Ca cations. In Akzhar pillared clays the quantity of $\mathrm{Zr}$ is $36.3 \%$ and in Karatau pillared clay it is $35.1 \%$. As expected, the content of $\mathrm{Fe}$ on the $\mathrm{Fe} / \mathrm{Cu} / \mathrm{Zr}$-PILCs increases in the modified clays in comparison with the natural clays, suggesting the exchange and fixation of the intercalating metals in the interlayer space. This incorporation is particularly noticed on $\mathrm{Fe} / \mathrm{Cu} / \mathrm{Zr}$-APILC, with the presence of $22.8 \%$ of $\mathrm{Fe}$ in the $\mathrm{Fe} / \mathrm{Cu} / \mathrm{Zr}$-APILC, against $7.9 \%$ in the corresponding natural clay (ANC), whereas $11.5 \%$ of Fe was reached in the $\mathrm{Fe} / \mathrm{Cu} / \mathrm{Zr}-\mathrm{KPILC}$, against $9.9 \%$. However, in the $\mathrm{Fe} / \mathrm{Cu} / \mathrm{Zr}-\mathrm{KPILC}$, the increment of $\mathrm{Cu}$ and $\mathrm{Zr}$ content was higher, reaching 9.6 and 5.1\%, respectively; whereas 6.1 and $0.9 \%$ were achieved in the $\mathrm{Fe} / \mathrm{Cu} / \mathrm{Zr}$-APILC. The total weight percentage in the three metals for $\mathrm{Fe} / \mathrm{Cu} / \mathrm{Zr}$-APILC and $\mathrm{Fe} / \mathrm{Cu} / \mathrm{Zr}-\mathrm{KPILC}$ resulted in 26.2 and $29.8 \%$, respectively. It is also evidenced that the solids modified with $\mathrm{Fe} / \mathrm{Cu} / \mathrm{Zr}$ have lower $\mathrm{Si} / \mathrm{Al}$ ratios $(\mathrm{Si} / \mathrm{Al}<3.7)$ than in the $\mathrm{Zr}$-PILCs $(\mathrm{Si} / \mathrm{Al}>$ 4.1), meaning that oxides got preferentially stabilized in the interlayer space of the clay, following the targeted cationic exchange mechanism [29]. Several works $[13,14,30-32]$ dealing with different natural clays, modified with $\mathrm{Al}, \mathrm{Fe}$ and $\mathrm{Cu}$ metal cations to produce pillared interlayered catalysts $(\mathrm{Al} / \mathrm{Fe}, \mathrm{Al} / \mathrm{Cu}$ and $\mathrm{Al} / \mathrm{Cu} / \mathrm{Fe})$, show to incre- ment appreciably the catalytic activity of the respective natural clays in CWPO processes.

\subsubsection{Fourier transforms infrared spectroscopy}

The FTIR spectra of the ANC and of the APILCs are shown in Fig. 2. The general shape of all spectra is similar, indicating that the layered crystal structure of the natural clay is not strongly affected by the pillaring process. Peaks between the FTIR spectra of the pillared samples and of the natural clay suggest its successful modification.

The broad band at $3,444 \mathrm{~cm}^{-1}$ is due to bending and stretching vibrations of $\mathrm{H}_{2} \mathrm{O}$ and the band at $1,631 \mathrm{~cm}^{-1}$ is due to an overtone of the bending vibration of water [33]. The band at $1,046 \mathrm{~cm}^{-1}$ is attributed to the stretching vibration of the Si-O bond, while the band corresponding to the bending vibration was observed at $875 \mathrm{~cm}^{-1}$. The bending vibration bands of the Si-O-Si and Si-O bonds indicate that the natural clay holds two types of layered structures, one related to plane layer structure, and the other related to the interlayer structure with the appearance of the Si-O band at $536 \mathrm{~cm}^{-1}$.

The absorption bands at 3,622, 2,922 and 2,852 $\mathrm{cm}^{-1}$ can be ascribed to $-\mathrm{OH}$ groups, typically found in other clays [33,34]. The presence of calcite in the raw material can be observed by the band found at $1,431 \mathrm{~cm}^{-1}$ [27]. This corroborates the presence of calcite in the natural clays observed by XRD analysis. As can be observed, the carbonate band significantly decreases after the pillaring process, likely due to exchange of the ions.

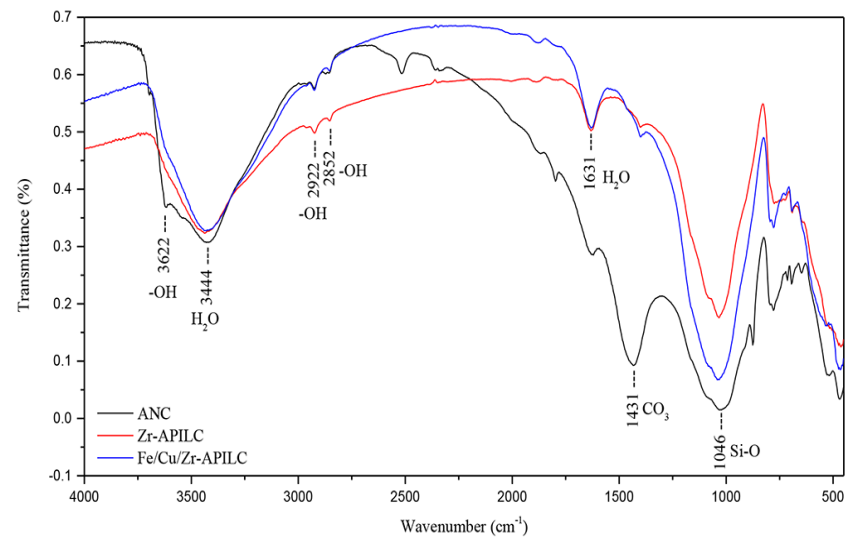

Fig. 2. FTIR spectra of ANC and APILCs. 


\subsubsection{Microscopy}

The surface morphologies of the natural clays and of the PILCs prepared were observed by SEM and by TEM. In this work, SEM proves to be ideally suited for studying the configuration, texture of clay samples [35]. The corresponding SEM micrographs are shown in Fig. S1. Generally, the images of natural clays show layered and smooth surfaces. However, ANC and KNC (Fig. S1(A)-(B)) are not so smoother when compared to other non-pillared clays, such as the bentonite [33,36-40], whose surface is modified after pillarization showing a rougher surface and more porosity. The samples prepared by pillarization of ANC and KNC show a slight modification regarding the surface (slightly darker and rougher) and it is possible to observe higher particles when compared to the natural precursors.

The micrographs obtained by TEM analysis, in dark field mode, with natural and pillared clays are shown in Fig. 3. On the TEM images it is possible to observe characteristics of the materials, such as the stress, its crystallization, morphology and even its holography. On the TEM images of pillared clays shown in dark field mode the defects are evidenced, as well as fine particles present in the material, visible as dark-colored particles. These particles correspond to external aggregates of $\mathrm{Zr}$ which were used to modify the natural clays. This observation means that the impregnation of $\mathrm{Zr}$ on the natural clays also takes place along with its pillarization, likely due to an excess of the $\mathrm{Zr}$ precursor used. The phenomena has been also observed by other authors [41]. According with Fig.
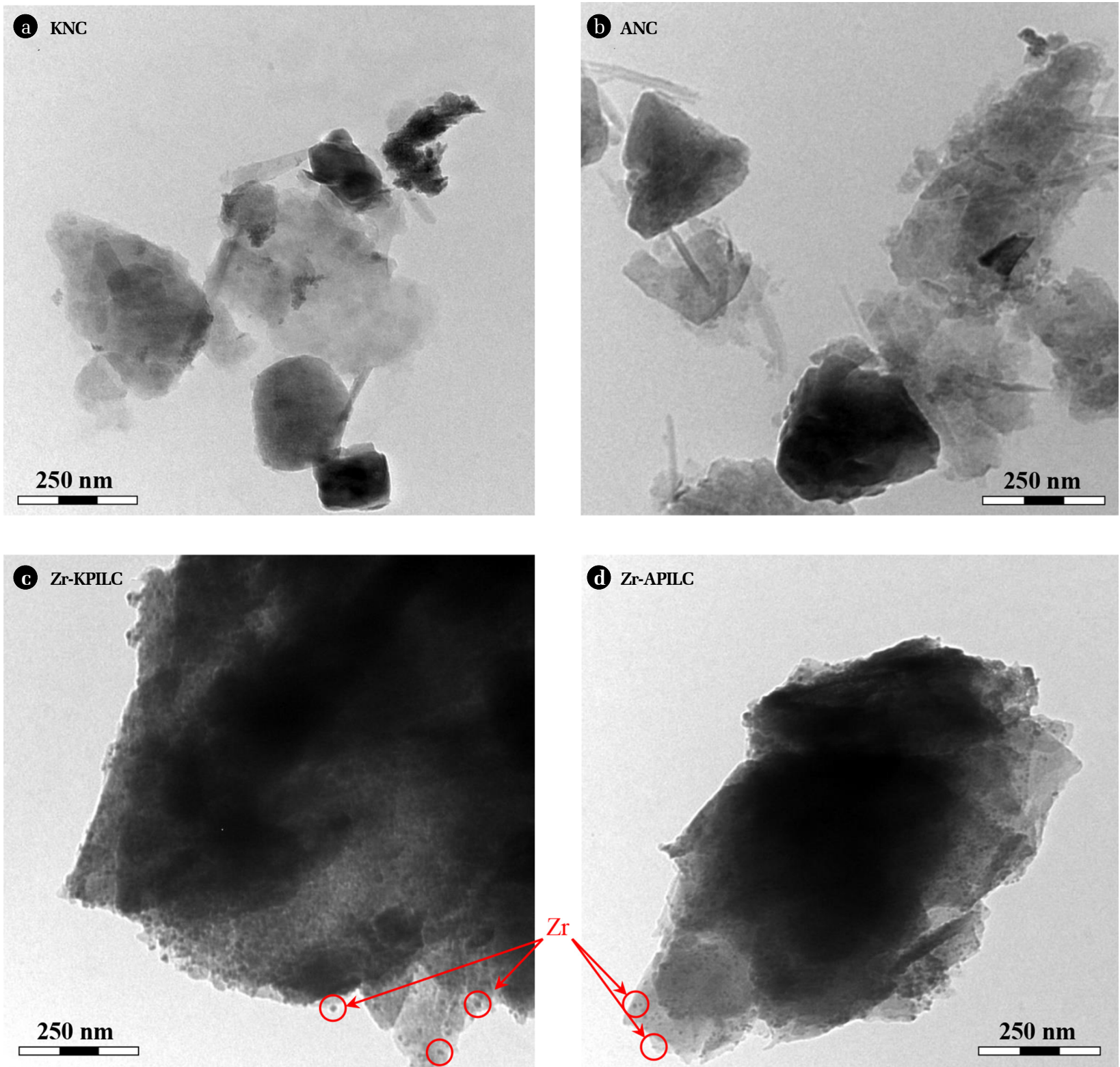

Fig. 3. TEM micrographs, in dark field mode, for (a-b) natural clays, (c-d) Zr-PILCs. 
3, the Zirconia particles were highly dispersed on the natural clays, with some being anchored inside the natural materials. The $\mathrm{Zr}$ impregnation of the clays with high dispersion confers more active sites for the CWPO of 4-NP on the developed materials.

\subsection{5. $\mathrm{pH}_{\mathrm{PZC}}$ determination}

The $\mathrm{pH}$ at which the net total particle charge is zero is called the point of zero charge $\left(p H_{P Z C}\right)$, or $p H_{P Z C}$, which is one of the most important parameters used to describe variable charge surfaces. The $\mathrm{pH}_{P Z C}$ of the different natural clays and PILCs used in this work are shown in Table S2. The results reveal that ANC and KNC have clearly basic character, since the values of $p H_{P Z C}$ obtained for those clays were 9.3 and 9.1, respectively. However, the intercalation procedures used leads to a decrease of the basic character of the clays, resulting in $\mathrm{pH}_{P Z C}$ values lower than 6.3 for all PILC materials. Concretely, the intercalation of $\mathrm{Zr}$ species produced a shift of $\mathrm{pH}_{P Z C}$ from 9.3 (ANC) to 6.3 (Zr-APILC), and from 9.1 (KNC) to 6.1 (Zr-KPILC), for Akzhar and Karatau clays, respectively. Regarding the trimetallic $\mathrm{Fe} / \mathrm{Cu} / \mathrm{Zr}-\mathrm{PILCs}$, similar $p H_{P Z C}$ decreases were observed, shifts to 6.2 and 6.0 being obtained for $\mathrm{Fe} / \mathrm{Cu} / \mathrm{Zr}-\mathrm{Akzhar}$ and $\mathrm{Fe} / \mathrm{Cu} / \mathrm{Zr}-\mathrm{Karatau}$ pillared clays, respectively. These values are in good agreement with the $\mathrm{pH}_{P Z C}$ values of $\mathrm{Zr}$ based pillared clays reported elsewhere [42]. The surface chemistry of the prepared PILC materials may thus be characterized as having a nearly neutral character which, when in contact with acidic aqueous solutions, will make the surface become with a positive charge, thus favorable for the attraction of negative anions present in solution.

\subsection{CWPO of 4-NP}

\subsubsection{Screening of catalysts}

Our work aims to develop affordable and active catalysts based on natural and pillared clays modified with $\mathrm{Zr}$ and $\mathrm{Fe} / \mathrm{Cu} / \mathrm{Zr}$ for use in purification processes of wastewaters containing organic pollutants by CWPO. Fig. 4(a) shows the conversion of 4-NP as a function of reaction time, obtained with the two natural clays and the four pillared clays considered in this work. The pillared clays were found to have excellent catalytic properties in the oxidation of 4-NP. It should be noted that the initial natural clay is rather inactive when compared to the modified materials (pillared clays). While the natural clays achieved only $32 \%$ of 4 -NP conversion after $8 \mathrm{~h}$ of reaction, the materials modified with metals revealed $100 \%$ of $4-\mathrm{NP}$ conversion in just $4 \mathrm{~h}$ of reaction. The materials modified with $\mathrm{Fe} / \mathrm{Cu} / \mathrm{Zr}$ species show better results than the solids modified with $\mathrm{Zr}$ species. While the conversions observed with the clays modified only with $\mathrm{Zr}$ reaches $100 \%$ after $4 \mathrm{~h}$ of reaction, the $\mathrm{Fe} / \mathrm{Cu} / \mathrm{Zr}-\mathrm{KPILC}$ and $\mathrm{Fe} / \mathrm{Cu} / \mathrm{Zr}$-APILC show $100 \%$ conversion of $4-\mathrm{NP}$ in only $2 \mathrm{~h}$ of reaction. In all the experiments carried out with the natural clays, almost complete oxidation of 4-NP could only be obtained after $24 \mathrm{~h}$ of reaction (98\% conversion). The analysis of the results obtained clearly emphasizes that the pillared clays have much superior catalytic activity than the natural clays towards the removal of 4-NP by CWPO. Therefore, the importance on the modification of natural clays by $\mathrm{Zr}$, Fe and $\mathrm{Cu}$ cations to increase its catalytic activity in the CWPO of 4-NP is placed in evidence.

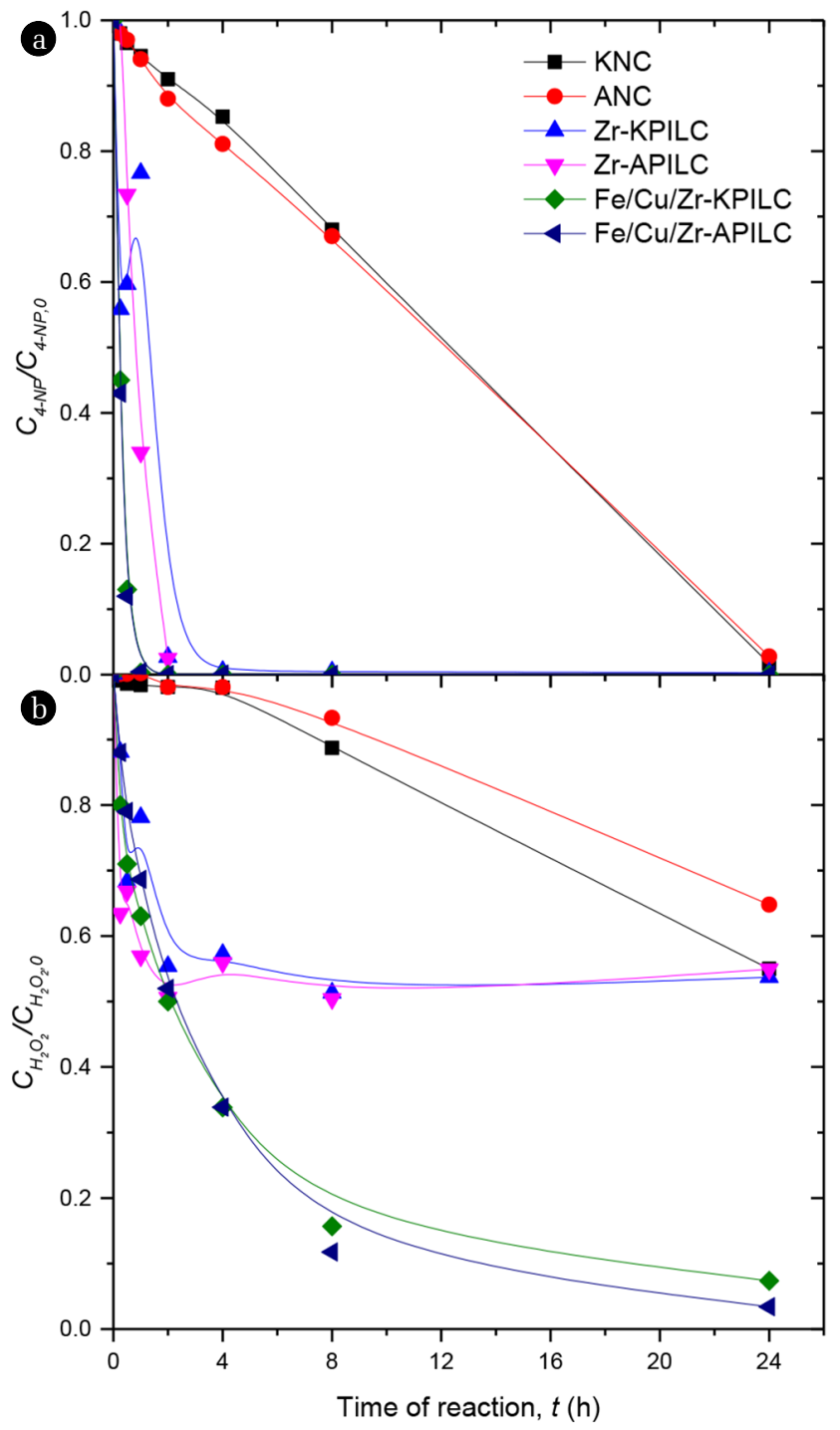

Fig. 4. Evolution of (a) 4-NP and (b) $\mathrm{H}_{2} \mathrm{O}_{2}$ against time of reaction by CWPO with the natural and pillared clays (Operating conditions: $\mathrm{C}_{4-\mathrm{NP}}=5 \mathrm{~g} \mathrm{~L}^{-1}, \mathrm{C}_{\mathrm{H}_{2} \mathrm{O}_{2}}=17.8 \mathrm{~g} \mathrm{~L}^{-1}, \mathrm{C}_{\text {cat }}=2.5 \mathrm{~g} \mathrm{~L}^{-1}$, initial $\mathrm{pH}=3.0$ and $\mathrm{T}=50^{\circ} \mathrm{C}$ ).

Fig. 4(b) shows the results obtained for $\mathrm{H}_{2} \mathrm{O}_{2}$ decomposition. It is clearly seen that the inclusion of $\mathrm{Fe}$ and $\mathrm{Cu}$ metals in the pillared clays drastically increases the activity of the materials for 4-NP oxidation. Nevertheless, the rate of $\mathrm{H}_{2} \mathrm{O}_{2}$ decomposition appears fairly similar for both Zr-KPILC and Zr-APILC during the first $4 \mathrm{~h}$ of reaction.

The conversion of 4-NP reached with any of the prepared PLCs is higher when compared with other catalysts used in previous works at the same operating conditions, such as graphene oxide materials [16] and carbon nanotubes [2]. The CWPO of 4-NP using clays as catalyst has been scarcely explored. Ayodele et al. [12] achieved a 4-NP degradation of $100 \%$ after $10 \mathrm{~min}$, but using higher concentration of the catalyst and hydrogen peroxide $\left(4 \mathrm{~g} \mathrm{~L}^{-1}\right.$ of Cu-pillared synthetic bentonite with $\mathrm{H}_{2} \mathrm{O}_{2}$ in an excess of $20 \%$ 
and light irradiation to assist the process) for much lower initial concentrations of 4-NP (75-100 ppm). Chirchi et al. [11] studied the degradation of similar initial concentrations of 4-NP (1 mM) in the presence of Fe- and Fe-Al-pillared synthetic bentonite (1 $\mathrm{g} \mathrm{L}^{-1}$ ), reaching complete conversions after $5 \mathrm{~h}$. The prepared KPILC and APILC allow to completely remove high loads of 4-NP (5 g $\left.\mathrm{L}^{-1}\right)$ in less time $(2 \mathrm{~h})$. The mineralization level obtained in the experiments was followed by measurements of the TOC conversion. The results obtained are represented in Fig. 5.

As expected, the removal of TOC is higher when pillared clays (conversion of TOC close to 70\%) are used and compared to the natural clays. The highest TOC removal (65.1\% after 8 h) was obtained with $\mathrm{Fe} / \mathrm{Cu} / \mathrm{Zr}-\mathrm{APILC}$. Under the same conditions, the

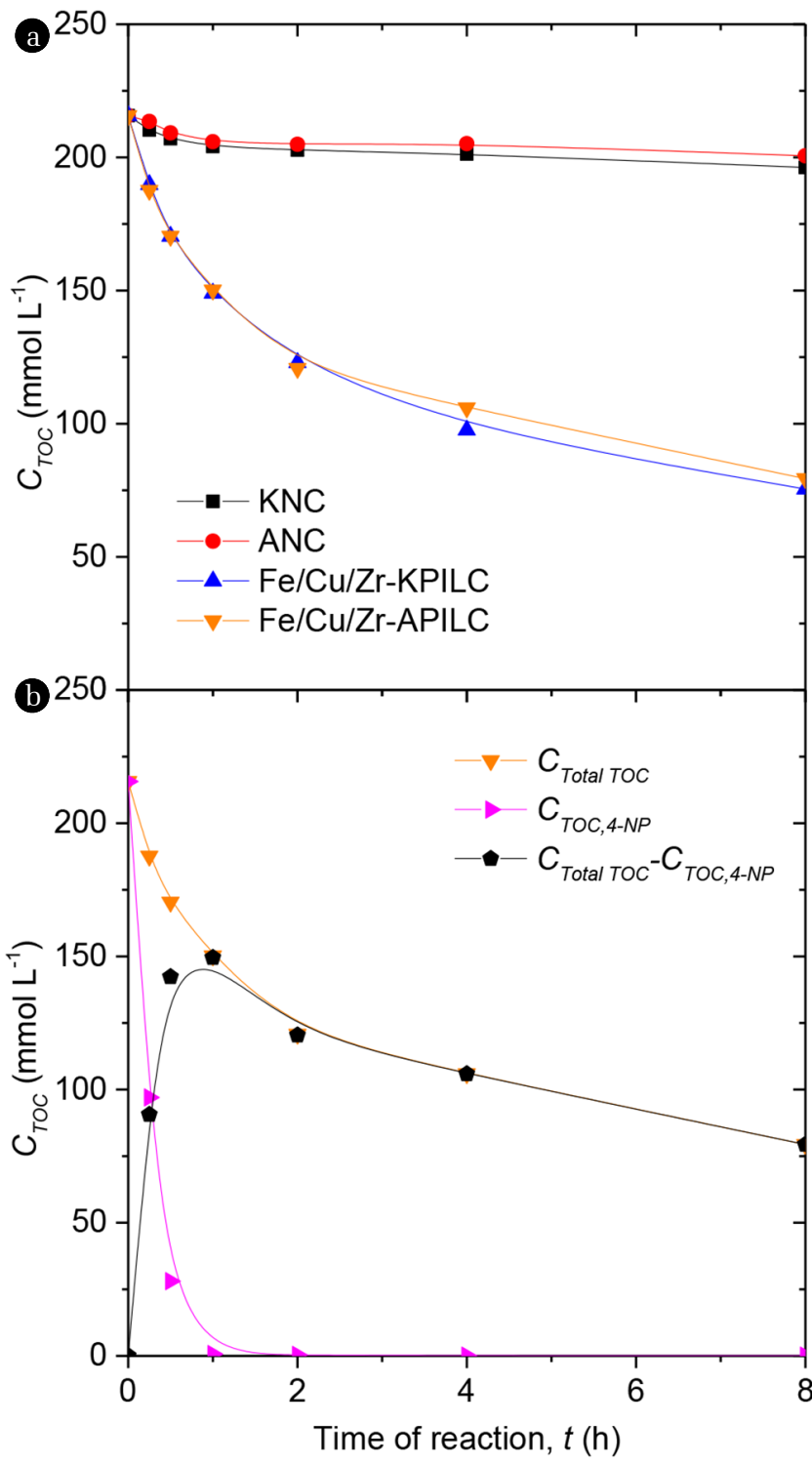

Fig. 5. Evolution of TOC removal in the CWPO of 4-NP with the (a) natural and $\mathrm{Fe} / \mathrm{Cu} / \mathrm{Zr}$-PILCs and (b) Fe/Cu/Zr-APILC (Operating conditions: $\mathrm{C}_{4-\mathrm{NP}}=5 \mathrm{~g} \mathrm{~L}^{-1}, \mathrm{C}_{\mathrm{H}_{2} \mathrm{O}_{2}}=17.8 \mathrm{~g} \mathrm{~L}^{-1}, \mathrm{C}_{\text {cat }}=2.5$ $\mathrm{g} \mathrm{L}^{-1}$, initial $\mathrm{pH}=3.0$ and $\mathrm{T}=50^{\circ} \mathrm{C}$ ). natural clays presented only $7.0 \%$ of TOC conversion after $8 \mathrm{~h}$. After $24 \mathrm{~h}$ (results not shown), the removals of TOC were 74.5 and $78.5 \%$ with $\mathrm{Fe} / \mathrm{Cu} / \mathrm{Zr}-\mathrm{KPILC}$ and $\mathrm{Fe} / \mathrm{Cu} / \mathrm{Zr}-\mathrm{APILC}$, respectively.

TOC conversions are considerably lower than 4-NP conversions, owing to the formation of more refractory products (intermediate compounds). Fig. 5(b) shows the evolution of TOC removal in the experiment carried out with $\mathrm{Fe} / \mathrm{Cu} / \mathrm{Zr}$-APILC, detailing the experimental TOC of the reaction media $\left(C_{\text {Total TOC }}\right)$, theoretical TOC of 4-NP (determined from the concentration of 4-NP by HPLC and taking into account its TOC contribution, $\left.C_{T O C, 4-N P}\right)$ and, finally, the resultant TOC obtained by the subtraction of the

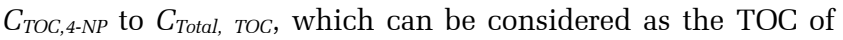
the oxidizable intermediates and final refractory products. As can be observed, after 4-NP oxidation, oxidizable compounds are produced, since the $C_{\text {Total }}$ тOC-$C_{T O C, 4-N P}$ curve show a maximum concentration close to $1 \mathrm{~h}$ of reaction time. Then, when all 4-NP is almost removed, the $C_{\text {Total }}$ TOC$^{-} C_{T O C, 4-N P}$ still decreases, evidencing the occurrence of oxidizable intermediates. According to previous works [16], the first stage leads to aromatic intermediates (4-nitrocathecol, phenol, hydroquinone, resorcinol, catechol and benzoquinone). Then these intermediates are further oxidized to low molecular weight carboxylic acids (malic, maleic, malonic, oxalic, acetic and formic acids), conferring to the aqueous media solution more acidity (final $\mathrm{pH}$ was found to be less than the initial $\mathrm{pH}$ of 3).

\subsubsection{Kinetic modeling}

Based on the TOC contributions described above (4-NP, oxidizable intermediates and refractory products), it is possible to describe the evolution of TOC by lumping into three blocks $\left(\mathrm{TOC}_{\mathrm{A}}, \mathrm{TOC}_{\mathrm{B}}\right.$ and $\mathrm{TOC}_{\mathrm{C}}$ ) to adjust the results to a simplified kinetic model (Eq. (4)-(6)).

$$
\begin{gathered}
C_{T O C}=C_{T O C, A}+C_{T O C, B}+C_{T O C, C} \\
T O C_{A} \stackrel{+H_{2} O_{2}, k_{1}}{\longrightarrow} C_{2}+T O C_{B} \stackrel{+H_{2} O_{2}, k_{3}}{\longrightarrow} C O_{2}+T O C_{C} \\
T O C_{A} \stackrel{+H_{2} O_{2}, k_{2}\left(<k_{1}\right)}{\longrightarrow} T O C_{B} \stackrel{+H_{2} O_{2}, k_{4}\left(<k_{3}\right)}{\longrightarrow} T O C_{C}
\end{gathered}
$$

$\mathrm{TOC}_{\mathrm{A}}$ represents the initial TOC and, thus, $\mathrm{TOC}_{\mathrm{A}}$ was assumed as the theoretical TOC of the 4-NP, $C_{T O C, 4-N P}$, which is converted to $\mathrm{CO}_{2}$ (justifying the decrease of TOC since the beginning of the CWPO process) and $\mathrm{TOC}_{\mathrm{B}}$, corresponding to the lump of the oxidizable intermediates. Once formed, these compounds also evolve to $\mathrm{CO}_{2}$ and to the final refractory products, $\mathrm{TOC}_{\mathrm{C}}$. According with this, the following equations can be considered (Eq. (7)-(8)):

$$
\begin{gathered}
T O C_{A}=C_{T o c, 4-N P} \\
T O C_{B}+T O C_{C}=C_{\text {Total TOC }}-C_{T O C, 4-N P}
\end{gathered}
$$

Simple power-law rate equations, of first reaction order with respect to each reactant $\left(\mathrm{H}_{2} \mathrm{O}_{2}, \mathrm{TOC}_{\mathrm{A}}, \mathrm{TOC}_{\mathrm{B}}\right.$ and $\left.\mathrm{TOC}_{\mathrm{C}}\right)$ have been checked for the prediction of $\mathrm{H}_{2} \mathrm{O}_{2}$ consumption and TOC removal, 
Table 2. Kinetic Parameters Obtained in Modeling of CWPO of 4-NP with Natural and Pillared Clays

\begin{tabular}{|c|c|c|c|c|c|}
\hline \multirow{2}{*}{ Catalyst } & \multicolumn{5}{|c|}{ Kinetic parameters } \\
\hline & $k_{H_{2} O_{2}}\left(\mathbf{L ~ g ~}^{-1} \mathbf{h}^{-1}\right)$ & $k_{1}\left(\mathbf{L} \mathbf{g}^{-1} \mathbf{h}^{-1}\right)$ & $k_{2}\left(\mathbf{L} \mathbf{g}^{-1} \mathbf{h}^{-1}\right)$ & $k_{3}\left(\mathbf{L} \mathbf{g}^{-1} \mathbf{h}^{-1}\right)$ & $k_{4}\left(\mathbf{L} \mathbf{g}^{-1} \mathbf{h}^{-1}\right)$ \\
\hline KNC & 0.062 & 0.037 & 0.024 & 0.128 & 0.128 \\
\hline ANC & 0.038 & 0.041 & 0.031 & 0.080 & 0.080 \\
\hline $\mathrm{Fe} / \mathrm{Cu} / \mathrm{Zr}-\mathrm{KPILC}$ & 2.216 & 2.803 & 2.365 & 0.568 & 0.215 \\
\hline $\mathrm{Fe} / \mathrm{Cu} / \mathrm{Zr}-\mathrm{APILC}$ & 2.501 & 2.752 & 2.750 & 1.328 & 0.484 \\
\hline
\end{tabular}

as follows (Eq. (9)-(12)):

$$
\begin{gathered}
-\frac{d C_{\mathrm{H}_{2} \mathrm{O}_{2}}}{d t}=k_{\mathrm{H}_{2} \mathrm{O}_{2}} C_{c a t} C_{\mathrm{H}_{2} \mathrm{O}_{2}} C_{T o c} \\
-\frac{d C_{T O C, 4-N P}}{d t}=k_{1} C_{c a t} C_{\mathrm{H}_{2} \mathrm{O}_{2}} C_{T O C, 4-N P} \\
\frac{d C_{T O C, B}}{d t}=k_{2} C_{c a t} C_{\mathrm{H}_{2} \mathrm{O}_{2}} C_{T O C, 4-N P}-k_{3} C_{c a t} C_{\mathrm{H}_{2} \mathrm{O}_{2}} C_{T O C, B} \\
\frac{d C_{T O C, C}}{d t}=k_{4} C_{c a t} C_{\mathrm{H}_{2} \mathrm{O}_{2}} C_{T O C, B}
\end{gathered}
$$

The numerical solution of these equations was solved by using the following initial conditions: $C_{\mathrm{H}_{2} \mathrm{O}_{2}}=C_{\mathrm{H}_{2} \mathrm{O} 2}, 0, C_{T O C, 4 \mathrm{NP}}=C_{\mathrm{TOC}, 4 \mathrm{NP}, 0}$, and $C_{T O C, B}=C_{T O C, C}=0 \mathrm{~mol} \mathrm{~L}^{-1}$ at $t_{0}=0$, in addition to consider that $C_{T O C}=C_{T O C, A}+C_{T O C, B}+C_{T O C, C}$. Table 2 summarize the values of the kinetic constants $\left(k_{\mathrm{H}_{2} \mathrm{O}_{2}} k_{1}, k_{2}, k_{3}\right.$ and $\left.k_{4}\right)$ proposed for the evolution of $\mathrm{H}_{2} \mathrm{O}_{2}$ and the lumped TOC in the CWPO of 4-NP with the natural and trimetallic-PILCs, according to Eq. (6)-(9). The values were determinate taking into account the concentration of the catalyst $\left(2.5 \mathrm{~g} \mathrm{~L}^{-1}\right)$ based on the Eq. (1). The solution of the equations were achieved by minimizing the SSR, which summarized also in Table 2 in addition to the determination coefficient $\left(R^{2}\right)$ for the simulated values of $\mathrm{H}_{2} \mathrm{O}_{2}$, 4-NP (as TOC of 4-NP) and TOC concentrations of reaction media.

As observed previously, the pillaring process increases substantially the catalytic activity of the clays in the CWPO of 4-NP, hence all kinetic constants obtained are significantly higher with $\mathrm{Fe} / \mathrm{Cu} / \mathrm{Zr}$-PILCs when compared to the natural clays. In fact, the kinetic constants of hydrogen peroxide consumption $\left(k_{\mathrm{H}_{2} \mathrm{O}_{2}}\right)$ and the first kinetic constants of $\mathrm{TOC}_{\mathrm{A}}$ removal $\left(k_{1}\right)$ show values up to fifty times larger with the $\mathrm{Fe} / \mathrm{Cu} / \mathrm{Zr}$-PILCs $\left(k_{\mathrm{H}_{2} \mathrm{O}_{2}}, k_{1}>2.2 \mathrm{~L}\right.$ $\left.\mathrm{g}^{-1} \mathrm{~h}^{-1}\right)$ than those with the natural clays $\left(k_{\mathrm{H}_{2} \mathrm{O}_{2}}, k_{1}<0.07 \mathrm{~L} \mathrm{~g}^{-1}\right.$ $\mathrm{h}^{-1}$ ), placing in evidence the far higher activity of the prepared PILCs when compared to the parent natural clays. The formation and oxidation of oxidizable organic intermediates $\left(\mathrm{TOC}_{\mathrm{B}}\right)$ is also considerable larger using the $\mathrm{Fe} / \mathrm{Cu} / \mathrm{Zr}$-PILCs $\left(k_{2}>2.3 \mathrm{~L} \mathrm{~g}^{-1} \mathrm{~h}^{-1}\right.$ and $k_{3}>0.5 \mathrm{~L} \mathrm{~g}^{-1} \mathrm{~h}^{-1}$, respectively), instead of the natural clays ( $k_{2}<0.4 \mathrm{~L} \mathrm{~g}^{-1} \mathrm{~h}^{-1}$ and $k_{3}<0.2 \mathrm{~L} \mathrm{~g}^{-1} \mathrm{~h}^{-1}$, respectively). The kinetic constant value relating the production of the refractory products $\left(\right.$ TOC $\left._{C}\right)$ is also higher when PILCs are used $\left(k_{4}>0.2 \mathrm{~L} \mathrm{~g}^{-1} \mathrm{~h}^{-1}\right)$. As expected, the kinetic constants relating to the formation of the subsequent lumped parts of TOC $\left(k_{2}\right.$ for $\mathrm{TOC}_{\mathrm{B}}$ and $k_{4}$ for
$\left.\mathrm{TOC}_{\mathrm{C}}\right)$ are lower than the kinetic constants regarding the oxidation of the previous TOC blocks $\left(k_{1}\right.$ and $k_{3}$, for the disappearance of $\mathrm{TOC}_{\mathrm{A}}$ and $\mathrm{TOC}_{\mathrm{B}}$, respectively). This is consequence of mineralization (formation of $\mathrm{CO}_{2}$ ) or, in other words, the disappearance of TOC during the experiments. According to these results, the initial mineralization is higher when using $\mathrm{Fe} / \mathrm{Cu} / \mathrm{Zr}-\mathrm{KPILC}\left(k_{1}=2.803 \mathrm{~L} \mathrm{~g}^{-1} \mathrm{~h}^{-1}\right.$ and $\left.k_{2}>2.365 \mathrm{~L} \mathrm{~g}^{-1} \mathrm{~h}^{-1}\right)$ than with $\mathrm{Fe} / \mathrm{Cu} / \mathrm{Zr}$-APILC $\left(k_{1}=2.752 \mathrm{~L} \mathrm{~g}^{-1} \mathrm{~h}^{-1}\right.$ and $k_{2}>2.750$ $\mathrm{L} \mathrm{g}^{-1} \mathrm{~h}^{-1}$ ), since the difference between the oxidation of $\mathrm{TOC}_{\mathrm{A}}$ $\left(k_{1}\right)$ and formation of oxidizable intermediates, TOC $\mathrm{B},\left(k_{2}\right)$ is higher. It is also possible to observe that the oxidation rate of these compounds $\left(\mathrm{TOC}_{\mathrm{B}}\right.$ ) show a lower kinetic constant when compared to the rate of disappearance of $\mathrm{TOC}_{\mathrm{A}}\left(k_{1}>k_{3}\right)$, putting in evidence that the oxidized intermediates are harder to oxidize compared to 4-NP.

The determination coefficients $\left(R^{2}\right)$ show a good agreement between the experimental and the simulated data for $\mathrm{H}_{2} \mathrm{O}_{2}$ and 4-NP concentrations. For TOC, a good determination coefficient is observed in the fitting of the experimental data obtained from $\mathrm{Fe} / \mathrm{Cu} / \mathrm{Zr}-\mathrm{PILCs}$. However, the regression of TOC does not show a good accuracy for the modelling of the data obtained with the natural clays (KNC and ANC). The results were maintained in order to compare the kinetic constant values obtained using the $\mathrm{Fe} / \mathrm{Cu} / \mathrm{Zr}$-PILCs with the corresponding natural clays. Nevertheless, the proposed kinetic model, which was fitted for all experimental data, is able to represent the data with accuracy (Fig. S2). The validation of this model is also illustrated by the parity plots shown in Fig. S3.

The evolution of TOC lumped by three defined blocks $\left(T O C_{A}\right.$, $T O C_{B}$ and $T O C_{C}$ ) with the $\mathrm{Fe} / \mathrm{Cu} / \mathrm{Zr}-\mathrm{PILCs}$ is depicted in Fig. 6. As can be observed, the sum of the three contributions of TOC allows representing suitably the evolution of TOC removal, which is in agreement with the experimental data (as symbols). According to the kinetic model, the occurrence of $T O C_{C}$ (refractory products) is perceptible since the beginning of reaction. Interestingly, the model predicts significant differences between the pillared clays for $T O C_{B}$ and $T O C_{C}$ profiles, since $T O C_{C}$ production is faster with the $\mathrm{Fe} / \mathrm{Cu} / \mathrm{Zr}$-APILC compared to $\mathrm{Fe} / \mathrm{Cu} / \mathrm{Zr}-\mathrm{KPILC}$

This is consequence of a faster oxidation of $T O C_{B}$ (higher value of $k_{3}$ with $\mathrm{Fe} / \mathrm{Cu} / \mathrm{Zr}$-APILC). Accordingly, $T O C_{B}$ evolution with $\mathrm{Fe} / \mathrm{Cu} / \mathrm{Zr}$-APILC describes the maximum concentration value (24 min) before than Fe/Cu/Zr-KPILC (36 min). This means that the $\mathrm{Fe} / \mathrm{Cu} / \mathrm{Zr}-\mathrm{APILC}$ is more active in the CWPO of 4-NP (the degradation of the pollutant is faster). However the concentration of $T O C_{B}$ with this catalyst at $8 \mathrm{~h}$ is close to $0 \mathrm{mmol} \mathrm{L}^{-1}$ and all TOC of the aqueous medium is consequence of the refractory products 


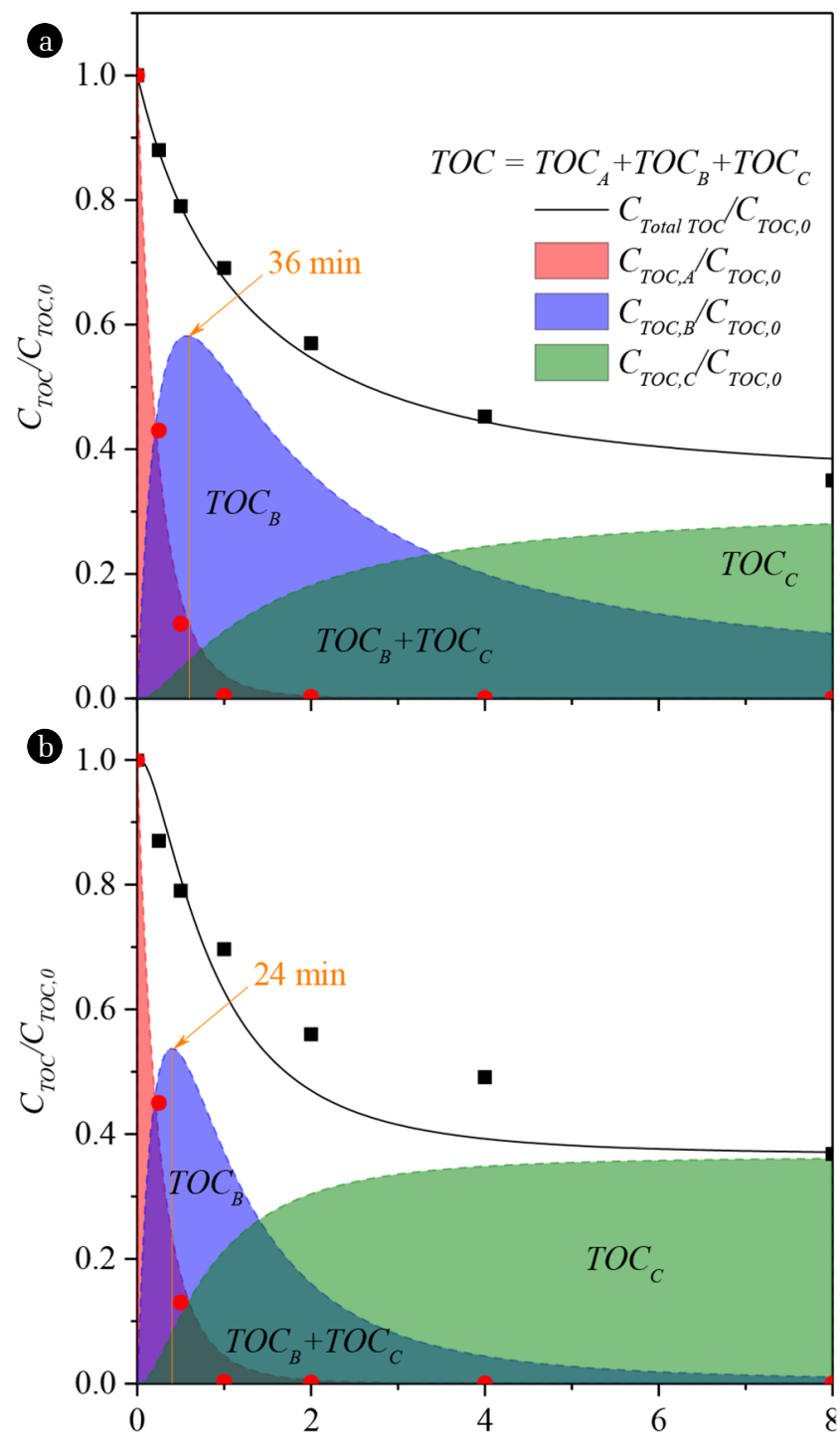

Time of reaction $(\mathrm{h})$

Fig. 6. Evolution of the simulated lumped TOC removal (symbols as experimental data of TOC and theoretical TOC contribution of 4-NP) in the CWPO of 4-NP with Fe/Cu/Zr-PILCs from (a) Karatau and (b) Akzhar (Operating conditions: $C_{4-\mathrm{NP}}=5 \mathrm{~g} \mathrm{~L}^{-1}$, $\mathrm{C}_{\mathrm{H}_{2} \mathrm{O}_{2}}=17.8 \mathrm{~g} \mathrm{~L}^{-1}, \mathrm{C}_{\text {cat }}=2.5 \mathrm{~g} \mathrm{~L}^{1}$, initial $\mathrm{pH}=3.0$ and $\mathrm{T}$ $=50^{\circ} \mathrm{C}$ ).

$\left(T O C_{C}\right)$, thus not more TOC can be degraded. On the other hand, the concentration of $T O C_{B}$ is higher (10\% of the initial TOC) at $8 \mathrm{~h}$ with $\mathrm{Fe} / \mathrm{Cu} / \mathrm{Zr}-\mathrm{KPILC}$, hence it is possible to achieve a higher mineralization, degrading this oxidizable $T O C_{B}$ to be converted to TOC $_{C}$ and $\mathrm{CO}_{2}$.

\section{Conclusions}

$\mathrm{Zr}$ and $\mathrm{Fe} / \mathrm{Cu} / \mathrm{Zr}$-PILCs were prepared from natural clays of Karatau and Akzhar. The catalysts obtained by the simultaneous incorporation of $\mathrm{Fe}, \mathrm{Cu}$ and $\mathrm{Zr}$ cations are highly efficient in the oxidation of 4-NP in aqueous medium at very mild conditions $\left(50^{\circ} \mathrm{C}\right.$ and atmospheric pressure). Pillared clay materials showed higher catalytic activity in the oxidation of 4-NP when compared to the natural clays. A complete removal of the contaminant is achieved after $4 \mathrm{~h}$ when $\mathrm{Zr}$ pillared clays are used, whereas the removal is reached after $2 \mathrm{~h}$ when $\mathrm{Fe} / \mathrm{Cu} / \mathrm{Zr}$ pillared clays are considered. The highest mineralization was obtained with the $\mathrm{Fe} / \mathrm{Cu} / \mathrm{Zr}$-PILCs. By the subtraction of the theoretical organic carbon contribution of 4-NP to the measured TOC it is possible to observe the production of the oxidizable intermediates, since a maximum peak of concentration is observed. According to that, it is possible to propose a kinetic lumped model for TOC removal based in the initial TOC (corresponding to 4-NP), oxidizable intermediates and the refractory products. The kinetic model can be used to reproduce suitable the experimental data obtained in the CWPO of 4-NP with pillared clays.

\section{Acknowledgments}

This work was financially supported by M.KH. Dulati Taraz State University, through a research work mission carried out in the Associate Laboratory LSRE-LCM, Polytechnic Institute of Bragança, Portugal. This work is also a result of: Project “AIProcMat@N2020 - Advanced Industrial Processes and Materials for a Sustainable Northern Region of Portugal 2020", with the reference NORTE-01-0145-FEDER-000006, supported by Norte Portugal Regional Operational Programme (NORTE 2020), under the Portugal 2020 Partnership Agreement, through the European Regional Development Fund (ERDF); Associate Laboratory LSRE-LCM-UID/ EQU/50020/2019 - funded by national funds through FCT/MCTES (PIDDAC).

\section{References}

1. Shibutov M. Industry report: Water management in Kazakhstan. In: Switzerland Global Enterprise. 2017.

2. Martin-Martínez M, Ribeiro RS, Machado BF, et al. Role of nitrogen doping on the performance of carbon nanotube catalysts: A catalytic wet peroxide oxidation application. ChemCatChem 2016;8:2068-2078.

3. Azabou S, Najjar W, Bouaziz M, Ghorbel A, Sayadi S. A compact process for the treatment of olive mill wastewater by combining wet hydrogen peroxide catalytic oxidation and biological techniques. J. Hazard. Mater. 2010;183:62-69.

4. Molina CB, Casas JA, Zazo JA, Rodriguez JJ. A comparison of $\mathrm{Al}-\mathrm{Fe}$ and $\mathrm{Zr}-\mathrm{Fe}$ pillared clays for catalytic wet peroxide oxidation. Chem. Eng. J. 2006;118:29-35.

5. Díaz de Tuesta JL, García-Figueruelo C, Quintanilla A, Casas JA, Rodriguez JJ. Application of high-temperature Fenton oxidation for the treatment of sulfonation plant wastewater. J. Chem. Technol. Biotechnol. 2015;90:1839-1846.

6. Catrinescu C, Arsene D, Teodosiu C. Catalytic wet hydrogen peroxide oxidation of para-chlorophenol over $\mathrm{Al} / \mathrm{Fe}$ pillared 
clays (AlFePILCs) prepared from different host clays. Appl. Catal. B 2011;101:451-460.

7. Mojović Z, Banković P, Milutinović-Nikolić A, Dostanić J, Jović-Jovičić N, Jovanović D. Al,Cu-pillared clays as catalysts in environmental protection. Chem. Eng. J. 2009;154:149-155.

8. Galeano LA, Vicente MA, Gil A. Catalytic degradation of organic pollutants in aqueous streams by mixed $\mathrm{Al} / \mathrm{M}$-pillared clays $(\mathrm{M}=\mathrm{Fe}, \mathrm{Cu}, \mathrm{Mn})$. Catal. Rev. 2014;56:239-287.

9. Cool P, Vansant EF. Pillared clays: Preparation, characterization and applications. Synthesis Springer. Berlin: Springer; 2001. p. 265-288.

10. Gil A, Korili SA, Trujillano R, Vicente MA eds. Pillared clays and related catalysts. 1st ed. New York: Springer-Verlag; 2010.

11. Chirchi L, Ghorbel A. Use of various Fe-modified montmorillonite samples for 4-nitrophenol degradation by $\mathrm{H}_{2} \mathrm{O}_{2}$. Appl. Clay Sci. 2002;21:271-276.

12. Ayodele OB, Hameed BH. Synthesis of copper pillared bentonite ferrioxalate catalyst for degradation of 4-nitrophenol in visible light assisted Fenton process. J. Ind. Eng. Chem. 2013;19:966-974.

13. Minz S, Garg S, Gupta R. Catalytic wet peroxide oxidation of 4-nitrophenol over $\mathrm{Al}-\mathrm{Fe}, \mathrm{Al}-\mathrm{Cu}$ and $\mathrm{Al}-\mathrm{Cu}-\mathrm{Fe}$ pillared clays. Indian Chem. Eng. 2017;60:16-36.

14. Minz S, Garg S, Gupta R. Catalytic wet peroxide oxidation of 4-nitrophenol over Al-Fe PILC: Kinetic study using Fermi's equation and mechanistic pathways based on TOC reduction. Chem. Eng. Commun. 2018;205:667-679.

15. Zhang W, Xiao X, An T, et al. Kinetics, degradation pathway and reaction mechanism of advanced oxidation of 4-nitrophenol in water by a UV/ $\mathrm{H}_{2} \mathrm{O}_{2}$ process. J. Chem. Technol. Biotechnol. 2003;78:788-794.

16. Ribeiro RS, Silva AMT, Pastrana-Martínez LM, Figueiredo JL, Faria JL, Gomes HT. Graphene-based materials for the catalytic wet peroxide oxidation of highly concentrated 4-nitrophenol solutions. Catal. Today 2015;249:204-212.

17. Ribeiro RS, Silva AMT, Figueiredo JL, Faria JL, Gomes HT. The role of cobalt in bimetallic iron-cobalt magnetic carbon xerogels developed for catalytic wet peroxide oxidation. Catal. Today 2017;296:66-75.

18. Diaz de Tuesta J, Quintanilla A, Casas JA, Rodriguez JJ. Kinetic modeling of wet peroxide oxidation with a carbon black catalyst. Appl. Catal. B 2017;209:701-710.

19. Agency for toxic substances and diseases registry. Toxicologal profiles for nitrophenols: 2-nitrophenol, 4-nitrophenol. In: P.H.S. U.S. Dept. of Health \& Human Services, Agency for Toxic Substances and Diseases Registry; 1992. p. 1-104.

20. U.S. Environmental Protection Agency. Nitrophenols-Ambient water quality criteria. 1980. p. A1-C134.

21. Newcombe G, Hayes R, Drikas M. Granular activated carbon: Importance of surface properties in the adsorption of naturally occurring organics. Colloids Surf. A 1993;78:65-71.

22. Diaz de Tuesta JL, Quintanilla A, Casas JA, Rodriguez JJ. P-, B- and N-doped carbon black for the catalytic wet peroxide oxidation of phenol: Activity, stability and kinetic studies. Catal. Commun. 2017;102:131-135.

23. Pinho MT, Silva AMT, Fathy NA, Attia AA, Gomes HT, Faria JL. Activated carbon xerogel-chitosan composite materials for catalytic wet peroxide oxidation under intensified process conditions. J. Environ. Chem. Eng. 2015;3:1243-1251.

24. Gomes HT, Figueiredo JL, Faria JL. Catalytic wet air oxidation of olive mill wastewater. Catal. Today 2007;124:254-259.

25. Ribeiro RS, Rodrigues RO, Silva AMT, et al. Hybrid magnetic graphitic nanocomposites towards catalytic wet peroxide oxidation of the liquid effluent from a mechanical biological treatment plant for municipal solid waste. Appl. Catal. B 2017;219:645-657.

26. Fatimah I. Preparation of $\mathrm{ZrO}_{2} / \mathrm{Al}_{2} \mathrm{O}_{3}$-montmorillonite composite as catalyst for phenol hydroxylation. J. Adv. Res. 2014;5: 663-670.

27. Bruckman VJ, Wriessnig K. Improved soil carbonate determination by FT-IR and X-ray analysis. Environ. Chem. Lett. 2013;11:65-70.

28. Djeffal L, Abderrahmane S, Benzina M, Fourmentin M, Siffert S, Fourmentin S. Efficient degradation of phenol using natural clay as heterogeneous Fenton-like catalyst. Environ. Sci. Pollut. Res. Int. 2014;21:3331-3338.

29. Munoz HJ, Blanco C, Gil A, Vicente MA, Galeano LA. Preparation of $\mathrm{Al} / \mathrm{Fe}$-pillared clays: Effect of the starting mineral. Materials 2017;10:1-18.

30. Carriazo JG, Guelou E, Barrault J, Tatibouët JM, Moreno S. Catalytic wet peroxide oxidation of phenol over Al-Cu or Al-Fe modified clays. Appl. Clay Sci. 2003;22:303-308.

31. Galeano LA, Gil A, Vicente MA. Effect of the atomic active metal ratio in $\mathrm{Al} / \mathrm{Fe}-, \mathrm{Al} / \mathrm{Cu}$ - and $\mathrm{Al} /(\mathrm{Fe}-\mathrm{Cu})$-intercalating solutions on the physicochemical properties and catalytic activity of pillared clays in the CWPO of methyl orange. Appl. Catal. B 2010;100:271-281.

32. Khankhasaeva ST, Dashinamzhilova ET, Dambueva DV, Timofeeva MN. Catalytic properties of Fe-Cu-Al-montmorillonites in the oxidation of acid chrome dark blue azo dye. Kinet. Catal. 2013;54:307-313.

33. Zhou S, Zhang $\mathrm{C}, \mathrm{Hu} \mathrm{X}$, et al. Catalytic wet peroxide oxidation of 4-chlorophenol over Al-Fe-, Al-Cu-, and Al-Fe-Cu-pillared clays: Sensitivity, kinetics and mechanism. Appl. Clay Sci. 2014;95:275-283.

34. Jia F, Su J, Song S. Can natural muscovite be expanded? Colloids Surf. A 2015;471:19-25.

35. Bohor BF, Randall EH. Scanning electron microscopy of clays and clay minerals. Clays Clay Miner. 1971;19:49-54.

36. Wan D, Wang G-H, Li W-B, Chen K, Shu G. Synthesis of Fe-Al pillared bentonite and heterogeneous Fenton degradation of orange. Acta Physico-Chimica Sinica 2013;29:2429-2436.

37. Li W, Wan D, Wang G, Chen K, Hu Q, Lu L. Heterogeneous Fenton degradation of Orange II by immobilization of $\mathrm{Fe}_{3} \mathrm{O}_{4}$ nanoparticles onto Al-Fe pillared bentonite. Korean J. Chem. Eng. 2016;33:1557-1564.

38. Tomul F. Influence of synthesis conditions on the physicochemical properties and catalytic activity of Fe/Cr-pillared bentonites. J. Nanomater. 2012;2012:1-14.

39. Tomul F, Turgut Basoglu F, Canbay H. Determination of adsorptive and catalytic properties of copper, silver and iron contain titanium-pillared bentonite for the removal bisphenol A from aqueous solution. Appl. Surf. Sci. 2016;360:579-593.

40. Tomul F. The effect of ultrasonic treatment on iron-chromium pillared bentonite synthesis and catalytic wet peroxide oxidation of phenol. Appl. Clay Sci. 2016;120:121-134. 
41. Xue B, Guo H, Liu L, Chen M. Preparation, characterization and catalytic properties of yttrium-zirconium-pillared montmorillonite and their application in supported Ce catalysts. Clay Miner. 2018;50:211-219.
42. Mnasri-Ghnimi S, Frini-Srasra N. Effect of temperature synthesis on the catalytic performance of zirconium pillared interlayered clays for phenol oxidation. Modern Chem. Applic. 2017;5:1-9. 